\title{
Improving Database Quality by Applying Consistency Aspects to Naming Fields and Tables
}

\author{
Raissa Maringka \\ Amikom University, Yogyakarta, \\ 55281, Indonesia \\ raissa.1273@students.amikom.ac.id
}

\author{
Aulia Khoirunnita* \\ Amikom University, Yogyakarta, \\ 55281, Indonesia \\ aulia.1270@students.amikom.ac.id \\ * Corresponding author
}

\author{
Rodney Maringka \\ Amikom University, Yogyakarta, \\ 55281, Indonesia \\ rodney.1272@students.amikom.ac.id
}

\author{
Ema Utami \\ Amikom University, Yogyakarta, \\ 55281, Indonesia \\ ema.u@amikom.ac.id
}

\author{
Kusnawi \\ Amikom University, Yogyakarta, \\ 55281, Indonesia \\ khusnawi@amikom.ac.id
}

Received: 2021-02-20; Revised: 2021-03-04; Accepted: 2021-03-05; Published: 2021-03-14

\begin{abstract}
The database is one of the benchmarks that affect the quality of information systems. An effective information system certainly has a quality database. Aspects that can be measured to determine the quality of the database are aspects of truth, consistency, range, level of detail, completeness, minimalism, ability to integrate and readability. One of the mistakes that are often encountered in databases is related to the consistency aspect. Consistency aspects that are not paid much attention to its application can lead to data conflicts due to ambiguity and data duplication. This study aims to improve the quality of the database by applying consistency to the naming of fields and tables. A naming method to produce consistency in standardization was applied in this study.
\end{abstract}

Keywords- Database, Database Quality, SQL Server, Consistency Aspects

\section{INTRODUCTION}

An information system can be considered as an effective system if it has a good database. Quality databases can produce quality information systems (Batini \& Navathe 1986). A quality database is measured from several aspects, namely aspects of truth, aspects of consistency, aspects of reach, aspects of the level of detail, aspects of completeness, aspects of minimalism, aspects of ability to integrate and aspects of readability (Herden, 2001). One of the errors that is often encountered in databases is data conflicts due to ambiguity and data duplication or what is commonly called redundancy. Data conflicts arise due to the lack of attention to consistency aspects. Good database design is a design that can reduce data repetition (Marelli, 2018). The two main components in a database are tables and fields. The table contains several fields that hold related records. Field is a subject that has characteristics based on the table that contains it. Bad field names can show the characteristics of the table that contains them.
Therefore, good field naming also has an influence in designing a quality database (Pham, 2019). However, the database in an information system or application has become increasingly complex with the increasing number of tables, types of relations and data. In this case, it is necessary for information system or application developers who have a level of expertise in designing quality database schemes, because the risk of data redundancy, data ambiguity and errors in table relations can often occur. Inconsistent and long names of fields and tables can be one of the problems that can occur in complex databases (Taipalus, 2020). Too many tables and complicated relationships can lead to naming the same field in two different tables. To reduce the problems that can occur in naming fields and tables,

\section{RESEARCH METHODS}

\section{A. Flow of Review}

By conducting the Review stage, the database design concept can be tested for its accuracy (Herden, 2001). At this stage, the review flow in the research is carried out by determining the criteria to be tested through the results of data collection and literature review, making an implementation of the proposed method, optimizing the conceptual database scheme of the method that has been applied. The review flow can be seen in Picture 1 .

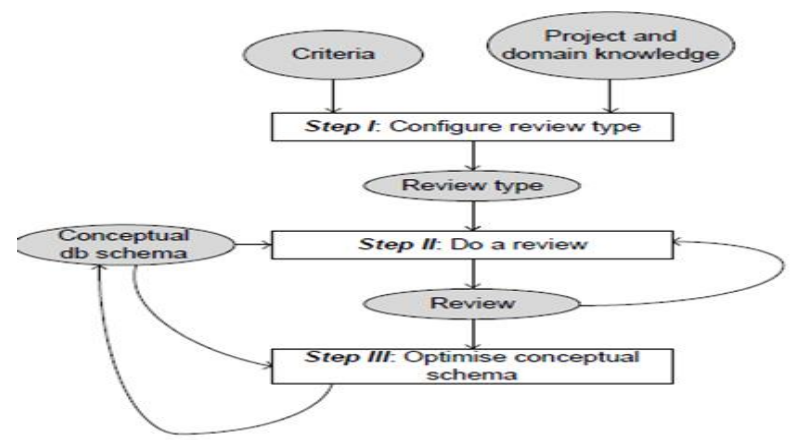

Picture 1. Review flow 


\section{B. Naming Method}

In the implementation of this research, the authors designed a method that contains stages for naming tables and fields as shown in Picture 2. The first stage is identification. At this stage it is necessary to identify the number of databases, the function of each database, the tables to be named and the function of each table in the database schema.

The second stage is grouping. Database schemes that have a number of databases more than one generally already have a good grouping based on the database. However, if the database is only one, it is necessary to group it based on table functions.

The third stage is naming or giving a name or label. The first naming is in the table, then the last naming is in the field. This naming process is based on table functions and groupings and still follows the applicable field naming standards. In this study, the naming method uses a combination of prefixes from each existing table or field function to form a specific code that will be easier to recognize and remember.

The next stage is documentation of the names of tables and fields that have been created to make it easier for application or system developers to search for field and function names if there are names that have not been remembered or for newcomers who will develop their applications.

The last stage is the implementation stage, namely by applying the names that have been made in tables and fields.

Naming fields and tables still follows the basic rules of database naming, namely not using spaces, if the name consists of two syllables, you can use the underscore to connect separate words or combine the two syllables, do not use words which are syntax of the database itself such as SELECT, CREATE, INSERT and so on, naming fields or tables must match the characteristics or functions of the fields and tables themselves and the latter can use prefixes and suffixes to simplify too long names (VM Le, 2019). The naming method can be seen in Picture 2 .

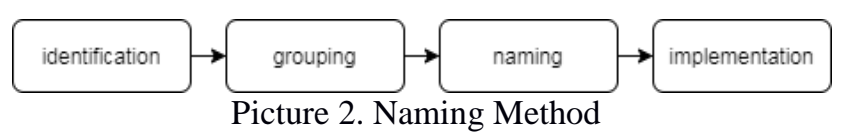

\section{RESULT AND DISCUSSION}

Picture 3 is a database diagram of the sales system. From the picture, it can be seen that the naming of fields is named according to the function and description of the field. Currently, the author will test the system to get a report on the remaining stock of goods by displaying the order date, order id, product name, type name and quantity. The sales database diagram can be seen in Picture 3.

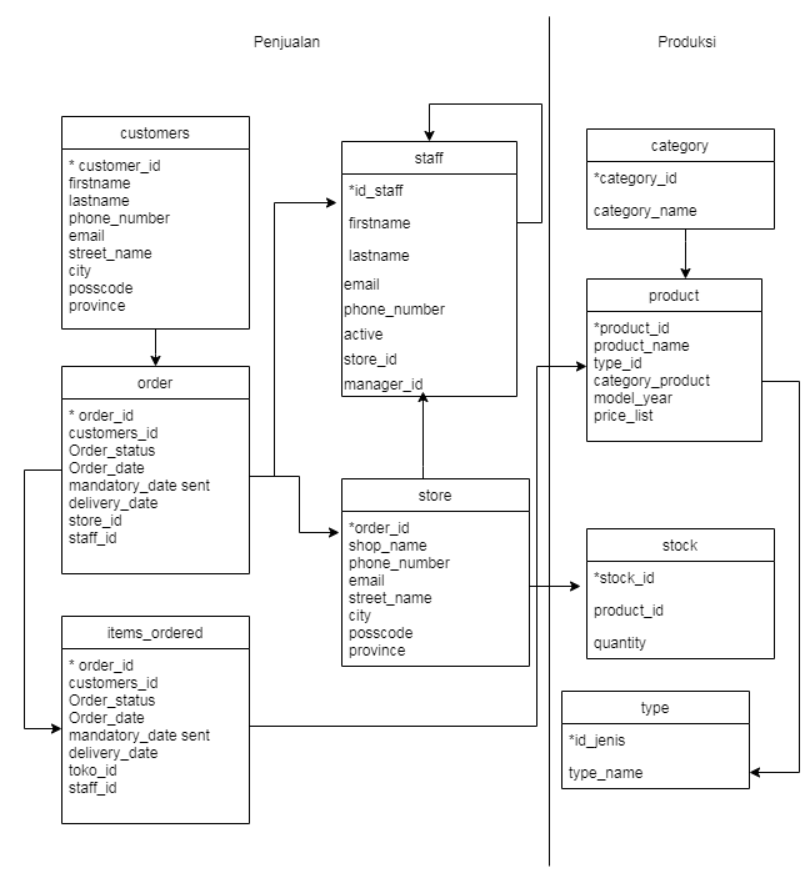

Picture 3. Goods Sales Database Diagram

It can be seen that there is a repetition of the field names in which the goods_porders and orders table have the same field name, namely dip Orders. Then in the goods_produk table, products and stocks also have the same field name, namely id_produk and finally the type table and product table have the same field, namely id_jenis. Actually, these same fields are needed because they are what make the related tables. The same field is a link between tables and is distinguished by using an alias or AS. For the tables that are still not too many and the database is not too big, this kind of thing is not a problem. But for databases with high complexity and lots of tables, this will be a problem that adds to the burden on application or system developers.

One solution to this problem is to provide unique names that do not cause ambiguity to fields and tables. The stages of naming fields and tables designed by the author can be applied in this case. The test results before the application of the naming method can be seen in Picture 4.

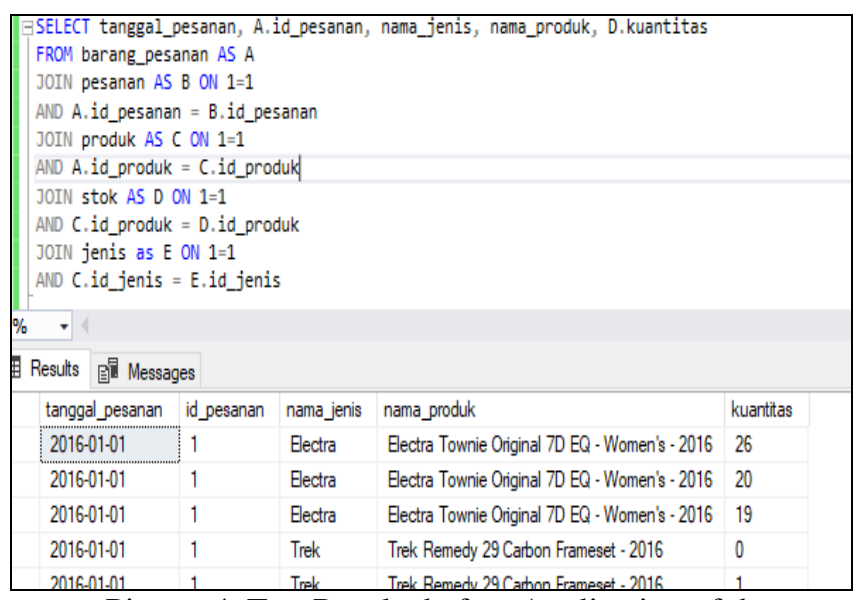

Picture 4. Test Results before Application of the Naming Method 
The test results using Query on Sql Server are shown as shown in Picture 5. The queries used are as follows.

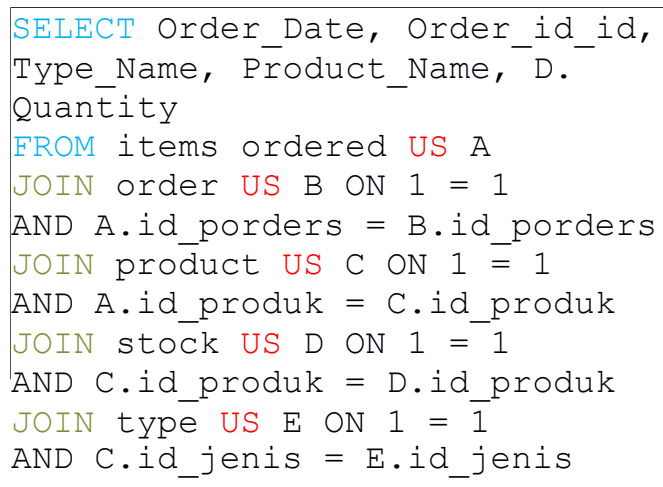

Picture 5. Query Testing

It can be seen that there is a repetition of the field names in which the goods_porders and orders table have the same field name, namely idap Orders. Then in the goods_produk table, products and stocks also have the same field name, namely id_produk and finally the type table and product table have the same field, namely id_jenis. Actually, these same fields are needed because they are what make the related tables. The same field is a link between tables and is distinguished by using an alias or AS. For the tables that are still not too many and the database is not too big, this kind of thing is not a problem. But for databases with high complexity and lots of tables, this will be a problem that adds to the burden on application or system developers. One solution to this problem is to provide unique names that do not cause ambiguity to fields and tables. The stages of naming fields and tables designed by the author can be applied in this case.

\section{A. Identification Stage}

The stages of identification can be seen in Picture 3 . The scheme of the sales data base has only one database with 9 tables, namely tables of customers, orders, goods_porders, staff, stores, categories, products, stocks and types. The naming of table names in the first database schema is adjusted according to the function of each table. For example, the table containing the order data is named the order.

\section{B. Grouping Stage}

After passing the identification stage, the next step is to identify the table based on its function. The grouping of tables based on their functions can be seen in table 1 . The explanation of the table is that there are two main functions in the database schema, namely the sales function and the production function, then the tables that have the same characteristics as the sales or production function can be made into one group same. The orders, goods Orders, customers, staff and shop tables are in the same group of table functions, namely the sales function. Tables of categories, products, stocks and types are in the same table function group, namely the Production table.

Table 1. Identification of Tables by Function.

\begin{tabular}{|c|c|}
\hline Sales & Production \\
\hline order & category \\
\hline items ordered & product \\
\hline customer & stock \\
\hline staff & type \\
\hline store & \\
\hline
\end{tabular}

\section{The Naming Stage}

The next stage is to give unique names to fields and tables. The unique names of fields and tables are derived from the universal language of a term. In this study, the Universal language used is English which can be seen in Table 2 in the Name column.

Table 2. Naming Tables by Function

\begin{tabular}{|c|c|c|c|c|c|}
\hline Function & Prefix & Name & $\begin{array}{c}\text { Data } \\
\text { Dictionary }\end{array}$ & Table & $\begin{array}{c}\text { Prefix } \\
\text { Table }\end{array}$ \\
\hline Sales & S & Customer & CUS & SCUS & SC \\
\hline Sales & S & Staffs & STF & SSTF & SF \\
\hline Sales & S & Store & STR & SSTR & SS \\
\hline Sales & S & Order & ORD & SORD & SO \\
\hline Sales & S & Order Item & OIT & SOIT & SI \\
\hline Production & P & Category & CAT & PCAT & PC \\
\hline Production & P & Product & PRO & PPRO & PP \\
\hline
\end{tabular}

. From combining the table function prefix and the Data Dictionary, a new unique table name is created with characteristics according to its function.

\section{Field Naming}

The process of naming fields is almost the same as naming a table. Each Table Name is made a Data Dictionary which is used as a standardization of naming systems. For example, for every name that ends with the word ID, the standard data dictionary is NO. So if the name is Customer ID, then the Data Dictionary is CUNO, if the name is Category ID, then the Data Dictionary is CANO. After the Data Dictionary in each field has been obtained, the next step is to combine the Data Dictionary with the table prefix that has been made in table 2. Start with the table prefix, then continue with the data dictionary. The naming process is accompanied by recording or bookkeeping on the data dictionary and prefixes of newly created fields and tables as a guide to standardizing the naming of fields and tables in the system. The existence of complete bookkeeping or data collection also supports aspects of database quality, 
namely aspects of the ability to integrate and readability. The field table can be seen in Table 3 .

Table 3. Field Naming

\begin{tabular}{|c|c|c|c|c|c|}
\hline Table & Description & Name & Dictionary Data & Prefix Table & Field Name \\
\hline SCUS & id pelanggan & customer ID & CUNO & $\mathrm{SC}$ & SCCUNO \\
\hline SCUS & nama depan & first name & $\mathrm{FN}$ & $\mathrm{SC}$ & SCFN \\
\hline SCUS & nama belakang & family name & FMN & $\mathrm{SC}$ & SCFMN \\
\hline SCUS & nomor telfon & phone number & $\mathrm{PN}$ & $\mathrm{SC}$ & SCPN \\
\hline SCUS & email & email & EML & $\mathrm{SC}$ & SCEML \\
\hline SCUS & nama jalan & street & STT & $\mathrm{SC}$ & SCSTT \\
\hline SCUS & kota & city & CTY & $\mathrm{SC}$ & SCCTY \\
\hline SCUS & kode pos & ZIP code & $\mathrm{ZC}$ & $\mathrm{SC}$ & SCZC \\
\hline SCUS & provinsi & state & ST & $\mathrm{SC}$ & SCST \\
\hline SORD & id pesanan & Order ID & ONO & $\mathrm{SO}$ & SOONO \\
\hline SORD & id pelanggan & Customer ID & CUNO & $\mathrm{SO}$ & SOCUNO \\
\hline SORD & status pesanan & Order Status & OSS & $\mathrm{SO}$ & SOOSS \\
\hline SORD & tanggal pesanan & Order Date & ODT & $\mathrm{SO}$ & SOODT \\
\hline SORD & tgl wajib kirim & Required Date & RDT & $\mathrm{SO}$ & SORDT \\
\hline SORD & tgl pengiriman & Shipped Date & SDT & $\mathrm{SO}$ & SOSDT \\
\hline SORD & id toko & Store ID & SRNO & $\mathrm{SO}$ & SOSRNO \\
\hline SORD & id staff & staff ID & SFNO & $\mathrm{SO}$ & SOSFNO \\
\hline SOIT & id pesanana & order id & ONO & SI & SIONO \\
\hline SOIT & id barang & item id & ITNO & SI & SIITNO \\
\hline SOIT & id produk & product id & PNO & SI & SIPNO \\
\hline SOIT & kuantitas & quantity & QTY & SI & SIQTY \\
\hline SOIT & daftar harga & list price & LP & SI & SILP \\
\hline SOIT & diskon & discount & $\mathrm{DC}$ & SI & SIDC \\
\hline SSTF & id staff & staff ID & SFNO & SF & SEFNO \\
\hline SSTF & nama depan & first name & $\mathrm{FN}$ & SF & SFFN \\
\hline SSTF & nama belakang & family name & FNM & SF & SFFNM \\
\hline SSTF & email & & EML & SF & SFEML \\
\hline SSTF & nomor telfon & phone number & $\mathrm{PN}$ & SF & SFPN \\
\hline SSTF & aktif & active & $\mathrm{AC}$ & SF & SFAC \\
\hline SSTF & id toko & store id & SRNO & SF & SFSRNO \\
\hline SSTF & id manager & manager id & MNO & SF & SFMNO \\
\hline SSTR & id toko & Store ID & SRNO & SS & SSSRNO \\
\hline SSTR & nama toko & store name & SRN & SS & SSSRN \\
\hline SSTR & nomor telfon & phone number & $\mathrm{PN}$ & SS & SSPN \\
\hline SSTR & email & & EML & SS & SSEML \\
\hline SSTR & nama jalan & street & STT & SS & SSSTT \\
\hline SSTR & kota & city & CTY & SS & SSCTY \\
\hline SSTR & kode pos & ZIP code & $\mathrm{ZC}$ & SS & SSZC \\
\hline SSTR & provinsi & state & ST & SS & SSST \\
\hline PCAT & id kategori & category id & CANO & $\mathrm{PC}$ & PCCANO \\
\hline PCAT & nama kategori & category name & $\mathrm{CN}$ & $\mathrm{PC}$ & PCCN \\
\hline PPRO & id product & product id & PNO & PP & PPPNO \\
\hline PPRO & nma produk & product name & PRN & $\mathrm{PP}$ & PPPRN \\
\hline PPRO & id jenis & brand id & $\mathrm{BNO}$ & PP & PPBNO \\
\hline PPRO & id kategori & category id & CANO & $\mathrm{PP}$ & PPCANO \\
\hline PPRO & tahun model & model year & MY & $\mathrm{PP}$ & PPMY \\
\hline PPRO & daftar harga & list price & LP & $\mathrm{PP}$ & PPLP \\
\hline PSTK & id stok & stock id & STNO & PS & PSSTNO \\
\hline PSTK & id produk & product id & PNO & PS & PSPNO \\
\hline PSTK & kuantitas & quantity & QTY & PS & PSQTY \\
\hline PBRD & id jenis & brand id & $\mathrm{BNO}$ & PB & PBBNO \\
\hline PBRD & nama jenis & brand name & $\mathrm{BN}$ & PB & PBBN \\
\hline
\end{tabular}

\section{E. Implementation Stage}

The last stage is implementation by creating tables and fields according to the names that have been designed in the documentation.

The results of the implementation of the new naming process can be seen in Picture 5. The longest name is only limited to six characters and the shortest name is only four characters. The names of the new tables with sales or sales functions are SORD (Order), SOIT (Order Item), SSTF (Staff), SSTR (Store), SCUS (Customer). The names of the new tables with production or production functions are PPRO (Product), PBRD (Brand), PCAT (Category)
After the implementation, the test is again carried out to get the same results as the initial test, but with a different syntax or query due to the new table and field names. The Database Diagram after the Naming Process can be seen in Picture 6 and the Test Results after the Naming Process can be seen in Picture 7. 


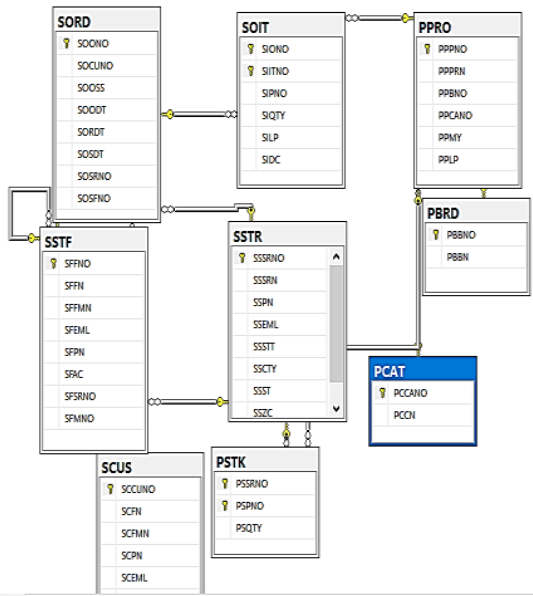

Picture 6. Database Diagram after the Naming Process

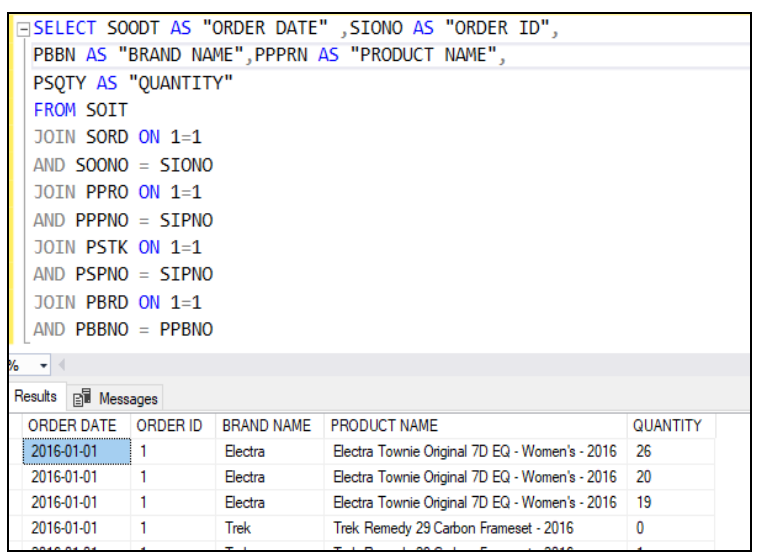

Picture 7. Testing Results after the Naming Process

You can see the difference before and after the naming process is applied where there is no ambiguity between the field names and the simpler syntax. Connecting fields between tables are still easily identified by looking at the similarities of the data dictionary. For example, the SOONO field and the SIONO field. Both of these fields have the same data dictionary, namely 'ONO' so it can be concluded that these fields. Image Testing Query 2 can be seen in Picture 8.

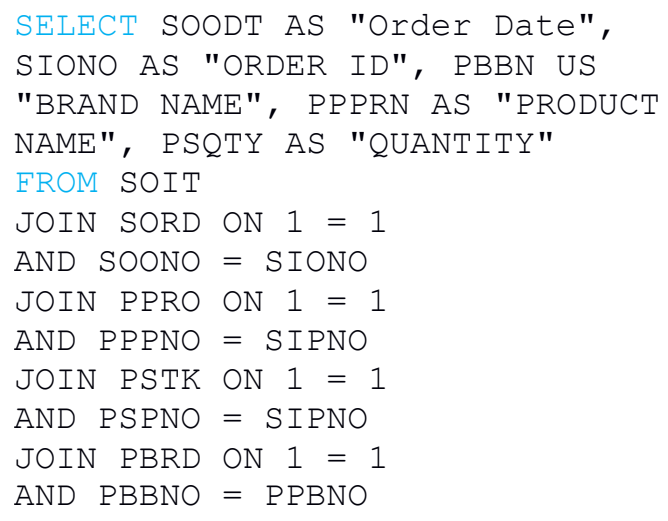

Picture 8. Testing Query 2

Based on the research conducted, it can be concluded that the method of naming fields and tables that have been designed is very suitable for databases that are still in the design stage and have not been implemented. If it has already been implemented, the process of changing table and field names will change all database schemas from the start, except for simple database schema types that don't have too many tables and fields, this is still possible. This method also makes it easier for developers to develop databases with a high level of complexity where the database has many tables, databases and many relationships.

Through this research, it is hoped that it can be used as a reference in database design. It is also hoped that further research will pay special attention to the effect of naming fields and tables in the database using other methods and approaches. It is recommended to use algorithms and tools that can generate field and table names automatically so that it makes it easier for developers to design databases that have a high level of complexity.

\section{REFERENCES}

Batini, C., Lenzerini, M. \& Navathe, SB, 1986. A comparative analysis of methodologies for database schema integration. ACM computing surveys (CSUR), 18 (4), pp.323-364.

Herden, O., 2001. Measuring quality of database schemas by reviewing-concept, criteria and tool. Oldenburg Research and Development Institute for Computer Science Tools and Systems, Escherweg, 2, p. 26121.

Le, VM, Soares, GA and Gulwani, S., Microsoft Technology Licensing LLC, 2019. SQL Query Formatting By Examples. US Patent Application 16 / 007,396.

Marelli, M. \& Amenta, S., 2018. A database of orthography-semantics consistency (OSC) estimates for 15,017 English words. Behavior research methods, 50 (4), pp. 1482-1495.

Pham, N., van Heck, RG, van Dam, JC, Schaap, PJ, Saccenti, E. and Suarez-Diez, M., 2019. Consistency, inconsistency, and ambiguity of metabolite names in biochemical databases used for genome-scale metabolic modeling. Metabolites, 9 (2), p. 28.

Taipalus, T., 2020, August. The Effects of Database Complexity on SQL Query Formulation (journalfirst). In 2020 46th Euromicro Conference on Software Engineering and Advanced Applications (SEAA) (pp. 185-185). IEEE. 